\title{
Seedling emergence response to early sowings in unprimed and osmoprimed seeds of fiber sorghums for energy biomass under semi-arid climate
}

\author{
Cristina Patanè, ${ }^{1}$ Alessandro Saita, ${ }^{2}$ Ashraf Tubeileh ${ }^{3}$ \\ ${ }^{1}$ Consiglio Nazionale delle Ricerche (CNR), Istituto per i Sistemi Agricoli e Forestali del \\ Mediterraneo (ISAFoM), Catania, Italy; ${ }^{2}$ Dipartimento di Scienze delle Produzioni Agrarie e \\ Alimentari (DISPA), Università di Catania, Italy; ${ }^{3}$ University of Guelph, Kemptville, Canada
}

\begin{abstract}
Fiber sorghum is a promising industrial crop for lignocellulosic biomass to be used for energy purposes. Limits to the adoption of early sowings (March-April) for this species are found in its thermal requirements for seed germination $\left(>10^{\circ} \mathrm{C}\right)$. Seed osmopriming has been found to decrease the impact of low temperatures on seed germination of sorghum in laboratory. In this study, unprimed (UP) and primed (P) seed germination behavior in both laboratory at cold temperatures and open field conditions under early sowings in a typically Mediterranean environment, was examined in four cold-tolerant cultivars of fiber sorghum (Padana 4, PR 811F, Jumbo and PSE 24213). Seed germination in UP at $8^{\circ} \mathrm{C}$ was on average $82.4 \%$, confirming the high cold-tolerance of all cultivars selected for the experiment. Germination was progressively delayed by the lowering of temperature from $25^{\circ} \mathrm{C}$ to $8^{\circ} \mathrm{C}$. Seed osmopriming was effective in promoting germination speed at all temperatures in laboratory. It also resulted in an appreciable lowering of thermal time requirements for final germination. With the earliest planting date (March 10), minimum soil temperatures during the first ten days never dropped below $10.2^{\circ} \mathrm{C}$, allow-
\end{abstract}

Correspondence: Dr. Cristina Patané, Consiglio Nazionale delle Ricerche (CNR), Istituto per i Sistemi Agricoli e Forestali del Mediterraneo (ISAFoM), Sede di Catania, Str.le V. Lancia, Zona Industriale, Blocco Palma I, 95121 Catania, Italy.

Tel. +39.095.292873 - Fax: +39.095 .292870 .

E-mail: cristinamaria.patane@cnr.it

Key words: Cold-tolerance, mean emergence time, osmopriming, plant emergence, sorghum, sowing date.

Acknowledgements: the research was conducted in the framework of the BIOSEA project funded by the Italian Ministry of Agriculture and Forestry (MIPAF). The authors are grateful to Mr. Salvatore La Rosa for his technical assistance in laboratory and field.

Received for publication: 28 October 2011.

Accepted for publication: 11 February 2012.

(C) Copyright C. Patanè et al., 2012

Licensee PAGEPress, Italy

Italian Journal of Agronomy 2012; 7:e30

doi:10.4081/ija.2012.e30

This article is distributed under the terms of the Creative Commons Attribution Noncommercial License (by-nc 3.0) which permits any noncommercial use, distribution, and reproduction in any medium, provided the original author(s) and source are credited. ing a final seedling emergence of $79.2 \%$ in UP. However, low soil temperatures slowed down the rate of seed germination. At the $2^{\text {nd }}$ sowing (end of March), daily maximum temperatures of soil exceeded $20^{\circ} \mathrm{C}$ but those minimum dropped below $10^{\circ} \mathrm{C}$, slightly depressing seed germination in UP (76.3\%). With the latest sowings (mid-April and early May), minimum soil temperatures always over exceeded minimum threshold for seed germination, allowing a regular seed germination in UP. Priming increased final emergence percentage in the two earliest sowings (those of March), whilst it enhanced the germination speed in all planting dates. Seed osmopriming also reduced thermal time requirements until the first seedling emerged from soil and promoted the seedling growth in all cultivars and sowing dates. These results suggest that it is possible to adopt early sowings (March) in cold-tolerant cultivars of sorghum under semi-arid climate, and that osmopriming allows the seed to partially overcome the limit imposed by cold soil to germination, contributing to a successful crop establishment when early plantings are adopted. Although the germination response to constant low temperatures in laboratory tests does not always provide a good index for predicting seedling emergence in soil under fluctuating uncontrolled temperatures, it may contribute to define desirable attributes for the identification of cultivars adapt to early sowings in the Mediterranean areas.

\section{Introduction}

Fiber sorghum [Sorghum bicolor (L.) Moench], as high-yielding species, is considered a promising industrial crop for the European Community, as a source of lignocellulosic biomass to be used for energy purposes (Cosentino et al., 2008; Mantineo et al., 2009). Field experiments conducted in different areas of Europe confirmed the high yield potential of this crop, at least under no water limitations (Cosentino, 1996; Cosentino et al., 1996).

Due to its tropical origin, in the semi-arid environments of South Italy this warm season species is cultivated in summer time, thus requiring the use of water for irrigation (Cosentino et al., 2002). Early sowings (March-April) in sorghum may allow the crop to escape part of the dry period, at least during the initial stages of growing season, and the root system to gain access to the water stored into the soil during the rainy season, thus saving irrigation water. Moreover, early sowings has been demonstrated to be more advantageous in terms of biomass yield as compared to late sowings (Cosentino et al., 2008). However, the thermal requirements of sorghum for seed germination $\left(>10^{\circ} \mathrm{C}\right)$ may limit the adoption of early sowings. Low temperature stress at planting may result in poor seedling establishment due to slow emergence rate or reduced emergence percentage (Singh, 1985). As a cold-stress susceptible crop, sorghum exhibits a poor early-season vigor and a reduced ability to compete with weeds under 
unfavorable thermal conditions (Ercoli et al., 2004).

Tolerance to cold soils is required in sorghum to take advantage from early planting dates, and the identification of cultivars less sensitive to cold during seed imbibition under open field conditions or seed treatments that may allow the seed to partially overcome the limit imposed by cold soil to seed germination, may lead to a successful crop establishment when early plantings are adopted. A preliminary screening under controlled temperatures revealed the existence of a significant genetic variability for cold tolerance among currently available genotypes of sorghum for energy biomass, at least under laboratory conditions (Saita et al., 2011). A rapid germination, besides a high emergence percentage, in cold soils, is also important because an emerged seedling is more resistant to diseases and soil crusting than is a germinating seed in the soil (Brar and Stewart, 1994).

Several approaches have been used to decrease the impact of low temperatures on seed germination. One seed treatment method that has been proved to be successful in improving seed germination is osmoconditioning or priming. Seed priming is a controlled hydration treatment at low water potential, that allows the seed to imbibe, so that pregerminative metabolism proceeds, but radical emergence is prevented (Bradford, 1986). Seed priming has been demonstrated to extend the lag phase of seed imbibition, thus permitting the activation of a large number of enzymes and greater mobilization of storage reserves (Khan et al., 1995). This metabolic advancement determines a more uniform and rapid radical emergence when seeds are transferred to higher water potential.

Seed osmopriming with polyethylene glycol (PEG) has been found to advance seed germination in sweet and fiber sorghum under cold, drought or salt stress in laboratory (Foti et al., 2002; Patanè et al., 2006; 2008; 2009). PEG, when compared to other osmotica (e.g. potassium salts), is more commonly used since it has no toxicity (Bradford, 1986). However, the results of germination tests made under constant temperatures do not always reflect field germination. Rapid emergence is a trait under genetic control but it depends on prevailing environmental factors. Indeed, frequent limiting seed-bed conditions including soil temperature, type and compaction, as well as sowing depth, may adversely affect germination. Discrepancies between germination and field emergence were found even under similar temperatures (Bacon et al., 1986). Therefore, the evaluation of germination characteristics of seeds under controlled environment, may provide not reliable results since not always reproducible to the uncontrolled environmental conditions under open field. Moreover, most priming studies have been limited to laboratory tests.

The present study aimed at assessing the seed germination behavior in four cultivars of fiber sorghum, under low constant temperatures in laboratory or under fluctuating temperatures when early sown in field under a typically Mediterranean environment, and estimating seed osmopriming effects in germination response under suboptimal temperatures in both controlled and uncontrolled conditions.

\section{Materials and methods}

\section{Plant material}

Seeds of four recent cultivars of fiber sorghum [Sorghum bicolor (L.) Moench]: Padana 4, PSE 24213 and Jumbo (Padana Sementi Elette, Tombolo, PD, Italy), PR 811F (Pioneer Seeds, Johnston, IA, USA), were used for the experiment. The cultivars are reported as cold-tolerant during germination, based on the results of preliminary laboratory tests (Saita et al., 2011).

Seeds were surface-sterilised in a $1 \%$ sodium hypochlorite solution, rinsed in distilled water and dried before the experiment.

\section{Germination tests in laboratory}

Seeds of the four cultivars of fiber sorghum were germinated at constant temperatures $(T)$ of $8^{\circ}, 10^{\circ}, 15^{\circ}, 20^{\circ}$ or $25^{\circ} \mathrm{C}$, with the last considered the optimum for seed germination of sorghum (ISTA, 1996), maintained in a thermostatically controlled incubator $\left( \pm 1^{\circ} \mathrm{C}\right)$.

Unprimed seeds (UP) were compared with osmoprimed seed (P). For the osmopriming treatment, seed subsamples of each cultivar were placed in $250 \mathrm{~mL}$ flasks containing $100 \mathrm{~mL}$ of a $250 \mathrm{~g} \mathrm{~L}^{-1}$ Polyethylene glycol 6000 (PEG) osmotic solution, corresponding to a $-0.86 \mathrm{MPa}$ water potential at $15^{\circ} \mathrm{C}$, according to Michel and Kaufmann (1973), for $72 \mathrm{~h}$.

The PEG treatment was chosen according to a previous research on sorghum seed germination (Foti et al., 2002). During osmopriming the seeds were soaked into the PEG solution in an incubator under dark and continuous aeration conditions in order to ensure normal seed respiration (Bujalski and Nienow 1991). The flasks were sealed with a hole on the top through which a narrow tube (approximately $3 \mathrm{~mm}$ inner diameter), connected to a small aquarium pump, insufflated air into solution. After $72 \mathrm{~h}$ priming the seeds were thoroughly rinsed with tap water first and distilled water after, dried with blotting paper and then left overnight at room temperature. After drying, the moisture content of primed seeds was similar to that of unprimed seeds. The seeds were used for the experiment after being surface-sterilised in sodium hypochlorite solution as above described. For both UP and P treatments, samples of 400 seeds (four replicates of 100 seeds each) were placed in covered 9-cm Petri dishes containing a single filter paper moistened with $7 \mathrm{~mL}$ of distilled water. Petri dishes were hermetically sealed with parafilm to prevent evaporation and then randomised within each temperature and incubated in the dark.

The seeds were kept in the dishes to assess germination. This was scored when radicle reached approximately $2 \mathrm{~mm}$ length and data were collected daily until no additional germination occurred. At the end of the experiment, the final percentage germination and the Mean Germination Time (MGT, days) were calculated, this last according to the equation (Scott et al., 1984):

$$
\mathrm{MGT}=\Sigma \mathrm{T}_{i} \mathrm{~N}_{i} / \mathrm{S}
$$

where:

$\mathrm{T}_{i}$ is the number of days counted from beginning of experiment

$\mathrm{N}_{i}$ is the number of seeds germinated on day $i$

$\mathrm{S}$ is the total number of seeds germinated.

\section{Sowing dates experiment in field}

The experiment was carried out in 2011 in a plan area of Eastern Sicily ( $10 \mathrm{~m}$ asl, $37^{\circ} 26^{\prime} \mathrm{N}$ Lat, $15^{\circ} 03^{\prime}$ E Long). The same cultivars Padana 4, PR811F, Jumbo and PSE24213 of fiber sorghum were adopted for the experiment. Seed lots for this experiment were the same as those used in laboratory tests. The effects of four sowing dates upon seedling emergence of these sorghums were examined. Sowing dates were the following: March $10^{\text {th }}$, March $28^{\text {th }}$, April $15^{\text {th }}$, May $2^{\text {nd }}$, with the last adopted as control, being the most appropriate period for sorghum planting in semi-arid areas. For each cultivar and sowing date, unprimed seeds (UP) and primed seeds (P) were used. Seeds of P were primed before sowing, following the same procedure as previously described for seed germination experiment.

For each seed treatment, samples of 150 seeds (three replicates of 50 seeds) were placed in pots of approximately $2 \mathrm{~L}$ of capacity, filled with a mixture of soil and compost $(1: 1 \mathrm{v} / \mathrm{v})$, at $\mathrm{a} \approx 2 \mathrm{~cm}$ soil depth. Soil moisture was kept at a good level, with irrigation (approx. $200 \mathrm{~mL}$ per pot at each watering) when required, so that soil water was not a limiting factor for seed germination and seedling emergence.

This last was scored daily in seedlings that reached approximately $1 \mathrm{~cm}$ length, and data were collected until no further visible seedling 
date, as a sum of heat units, according to the formula (Singh et al.,

emergence was observed.

Throughout the experiment, daily minimum and maximum soil (at a $2 \mathrm{~cm}$ depth) temperatures were monitored by means of a data logger (Escort iLog, Escort data loggers Inc., Buchanan, VA, USA) (Figure 1).

At the end of the experiment, the final percentage of seedlings emerged and Mean Emergence Time (MET, days) were calculated, the latter according to Eq. 1 (Scott et al., 1984):

$$
\mathrm{MET}=\Sigma \mathrm{T}_{i} \mathrm{~N}_{i} / \mathrm{S}
$$

where:

$\mathrm{T}_{i}$ is the number of days after sowing

$\mathrm{N}_{i}$ is the number of seedlings emerged on day $i$

$\mathrm{S}$ is the total number of seedlings emerged.

Seedling dry weight (mg) was finally measured for each planting date, cultivar and seed treatment, at 20 days after sowing, in six seedlings per replicate, within those first emerged, after drying in a thermoventilated oven at $65^{\circ} \mathrm{C}$ for $48 \mathrm{~h}$.

\section{Data analysis}

The course of cumulative values of seed germination with time (expressed on a thermal time scale), separately for UP and P, was described by a non-linear iterative regression method (SIGMAPLOT ${ }^{\circledR} 9.0$ software) using the following sigmoidal model with three parameters:

$$
y=\frac{a}{1+\left(\frac{x}{x_{0}}\right)^{b}}
$$

where $a$ is maximal value of $y$ (i.e. maximum germination), $x$ is time expressed in degree days $\left({ }^{\circ} \mathrm{Cd}\right)$ after seed imbibition, $x_{0}$ is thermal time $\left({ }^{\circ} \mathrm{Cd}\right)$ to reach $50 \%$ of maximum germination, $b$ is a fitting parameter of the curve.

Thermal time cumulated throughout the germination test was used to normalize the results from the different germination temperatures. It was calculated by progressively cumulating the values of the difference between each constant germination temperature $(T)$ and base temperature $\left(T_{\mathrm{b}}\right)$ for germination. A $T_{\mathrm{b}}$ of $6.6^{\circ} \mathrm{C}$ (Padana 4$), 6.2^{\circ} \mathrm{C}$ (PR811F), $7.4^{\circ} \mathrm{C}\left(\right.$ Jumbo) and $6.1^{\circ} \mathrm{C}$ (PSE24213) was assumed for $\theta_{\mathrm{T}}$ calculation, as estimated in a previous laboratory germination test conducted under a wide range of temperatures (Saita et al., 2011).

Thermal time requirements $\left(\theta_{\mathrm{T}},{ }^{\circ} \mathrm{Cd}\right)$ for achieving the first seedling emergence in soil were also calculated for each cultivar and sowing
1984):

$$
\theta_{\mathrm{T}}=\sum_{i=1}^{n}\left(T_{i}-T_{b}\right)
$$

where $T_{\mathrm{i}}$ is mean daily soil temperature $\left({ }^{\circ} \mathrm{C}\right)$ at day $\mathrm{i}$ as measured in field, $T_{\mathrm{b}}$ is the base temperature for germination and $n$ is the total number of days until the first seedling emerged from soil. $T_{\mathrm{b}}$ used for $\theta_{\mathrm{T}}$ calculation were those previously reported for germination tests in laboratory.

Data of final germination (for laboratory experiment) and emergence (for field experiment) percentages, previously arcsine transformed, and those of Mean Germination Time, Mean Emergence Time and seedling dry weight, were statistically analysed by a completely randomised two-way analysis of variance (ANOVA) using CoStat version 6.003 (CoHort Software). The analysis of variance was conducted separately within each temperature (laboratory experiment) or sowing date (field experiment), considering cultivar and seed treatment as fixed factors. When $\mathrm{F}$ ratios were significant, means were separated by the Student-Newman-Keuls (SNK) test $(\mathrm{P} \leq 0.05)$ (Snedecor and Cochran, 1989).

\section{Results and discussion}

\section{Effects of temperature on seed germination}

Results of final seed germination percentage in laboratory are reported in Table 1. Under optimal thermal conditions $\left(25^{\circ} \mathrm{C}\right)$, seed germination of UP exceeded the $93 \%$ in all cultivars, with Jumbo and $P R 811 F$ approaching $99 \%$ of seeds germinated. The lowering of temperature to $20^{\circ}$ and $15^{\circ} \mathrm{C}$ did not affect germination, which was 98.2 and $96.7 \%$, respectively, on average of cultivars. Seeds exposed to $10^{\circ} \mathrm{C}$ germinated for more than $90 \%$ (average of cultivars) and slightly reduced their germination capacity at the coldest temperature $\left(8^{\circ} \mathrm{C}, 82.4 \%\right.$ of seeds germinated). These data confirm the high cold-tolerance during germination of all cultivars selected for the experiment.

Germination tests revealed genetic differences for final germination percentage, at $15^{\circ} \mathrm{C}$ only. At this temperatures, seeds of PSE24123 germinated slightly but significantly less than those of the other cultivars.

Table 1. Effects of temperature and seed treatment on seed germination percentage in four cultivars of fiber sorghum.

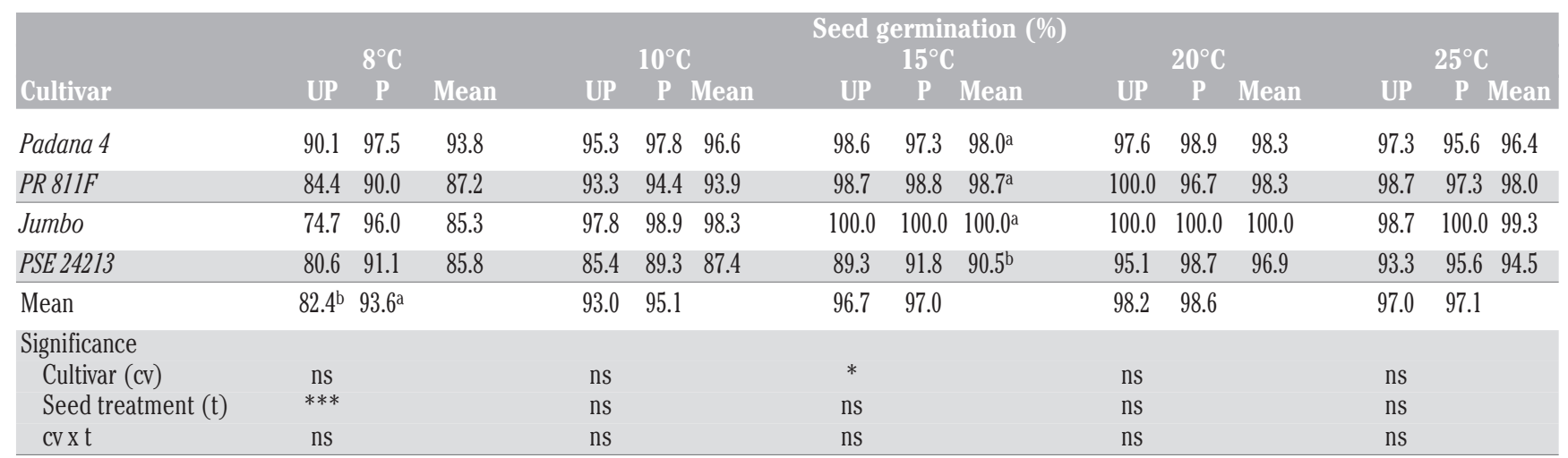

UP, unprimed seeds; P, osmoprimed seeds.; a,bdifferent letters indicate significant differences at 0.05 level according to the Student-Newman-Keuls (SNK) test; * P $\leq 0.05$; *** P $\leq 0.001$; ns, not significant. 
The differences in final germination percentage due to seed treatment were pronounced $(\mathrm{P} \leq 0.001)$ at the coolest temperature $\left(8^{\circ} \mathrm{C}\right)$ only, where seed treatment determined a $+14 \%$ increase of seeds germinated. Indeed, seed osmopriming did not exert any further beneficial effect on seed germination in terms of final percentage, since at temperatures greater than $8^{\circ} \mathrm{C}$ seed germination was fulfill in UP as well. A similar beneficial effect of osmopriming in promoting seed germination at low temperatures has been previously reported in sorghum (Foti et al., 2002; Patanè et al., 2006, 2008).

Germination was progressively delayed by the lowering of temperature from the optimum $\left(25^{\circ} \mathrm{C}\right)$ and seeds of UP exposed to $8^{\circ} \mathrm{C}$ took 17 days (MGT) to germinate (Table 2). According to Dunbabin et al. (1994), optimum temperature for a low MGT is greater than optimum temperature for germination. Indeed, at temperatures between $8^{\circ}$ and $15^{\circ} \mathrm{C}$ seed germination exceeded $80 \%$ in UP seeds, but it proceeded slower as temperature decreased from the optimum $\left(25^{\circ} \mathrm{C}\right)$. Differently than germination percentage, significant variation of MGT existed in cultivars of sorghum examined, at all temperatures. Seeds of PR811F germinated faster than those of the other cultivars.

The helpful effect of seed osmopriming on germination rate was significant at all temperatures. To better describe the overall efficacy of osmopriming on seed germination, data of cumulative germination percentage at all temperatures were plotted on a common thermal time scale (Figure 2). Each set of seed germination data, considered separately for seed treatment (UP and P), more or less adequately $\left(0.71 \leq \mathrm{R}^{2}\right.$ $\leq 98$ ) fitted the overall sigmoidal regression describing a common pattern at all temperatures (Table 3). Osmopriming resulted in an appreciable lowering of thermal time requirements until $50 \%$ of seeds germinated (lower values of $x_{0}$ coefficient in P than UP) in all cultivars, while maximal germination ( $a$ coefficient of the curve) did not much change with seed treatment, revealing a stronger effect of osmopriming on germination rate than on final germination percentage.

Similar positive effects of seed priming, more notable at cooler temperatures, on increasing germination rate, were reported by Hardegree and Van Vactor (2000) on grass seeds under field and simulated-field temperature regimes.

Table 2. Effects of temperature and seed treatment on mean germination time in four cultivars of fiber sorghum.

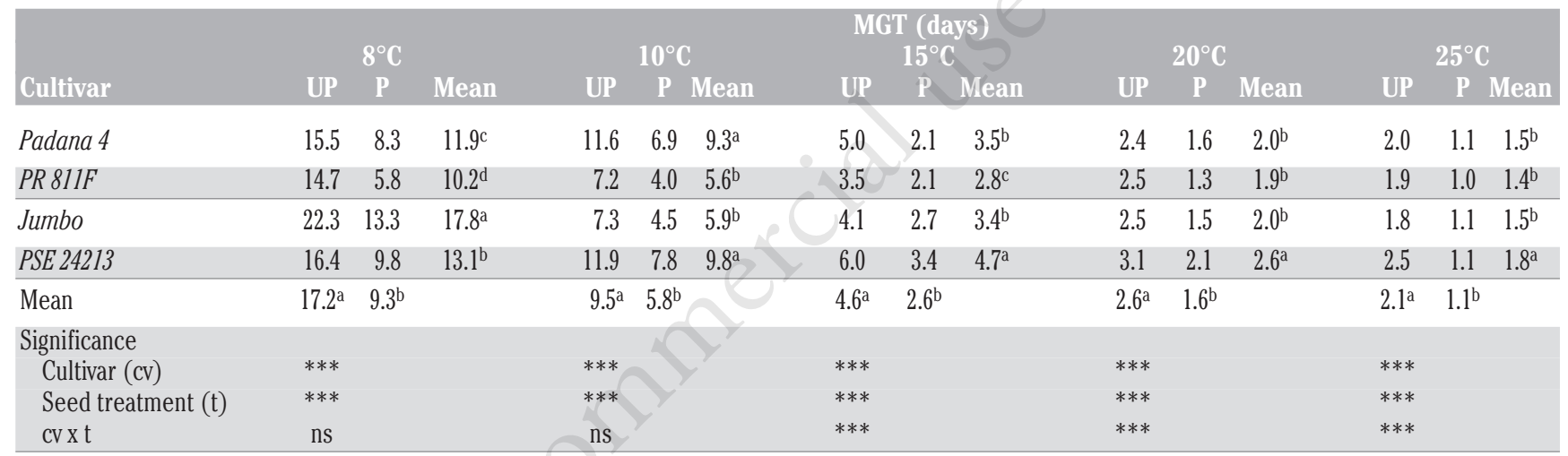

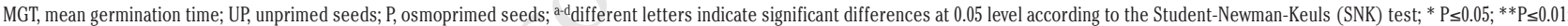
***P $\leq 0.001 ;$ ns, not significant.

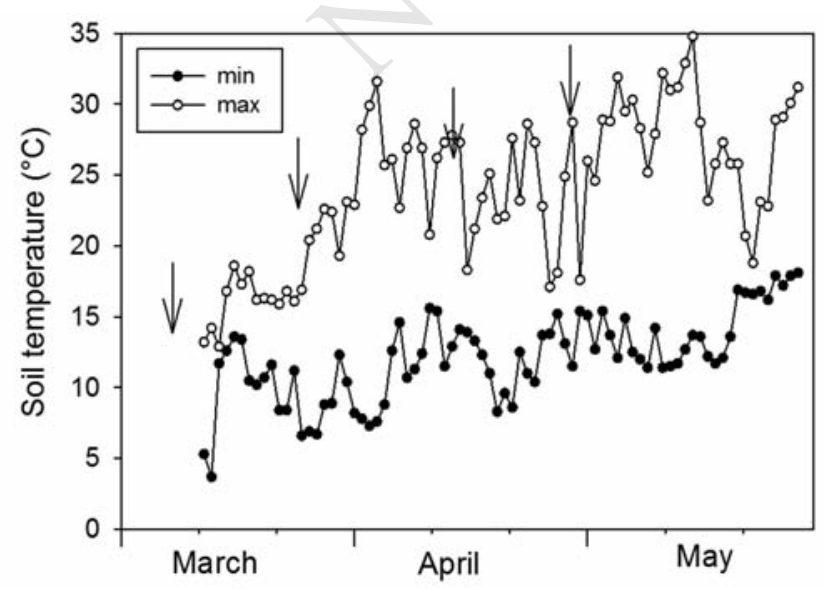

Figure 1. Minimum and maximum daily soil temperatures recorded during the experiment in field. Arrows indicate the sowing dates.

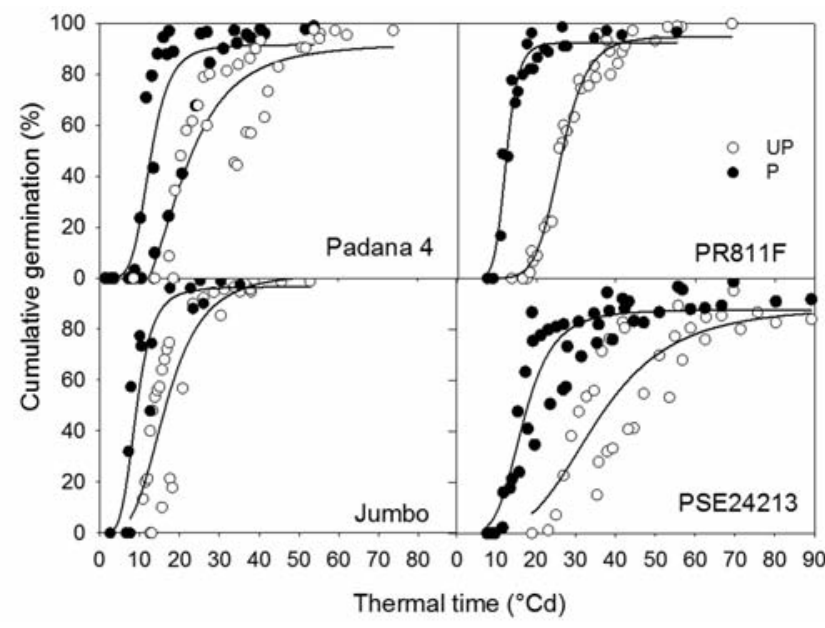

Figure 2. Cumulative germination percentages, plotted on a thermal time scale, in unprimed (UP, open symbols) and osmoprimed seeds (P, closed symbols) of four cultivars of fiber sorghum at $8^{\circ}-25^{\circ} \mathrm{C}$. Symbols represent the observed percentages at each temperature. 


\section{Effects of sowing date on seedling emergence}

Results of field experiment are summarized in Tables 4, 5, 6 and 7. With the earliest planting date, fluctuating minimum soil temperatures during the first ten days after sowing, although suboptimal $\left(16^{\circ} \mathrm{C}\right.$ the maximum, $10.3^{\circ} \mathrm{C}$ the minimum, on average), never dropped below $10.2^{\circ} \mathrm{C}$ (Figure 1), allowing a final seedling emergence which approached $79.2 \%$ after total 4 weeks (Table 4). However, low soil temperatures slowed down the rate of seed germination to 17.0 days (MET) in seeds of UP (Table 5). Seedling emergence started 13 days after planting.

At the $2^{\text {nd }}$ sowing (end of March), daily maximum temperatures of soil in the ten-day period after sowing always exceeded $20^{\circ} \mathrm{C}$ but those minimum dropped below $10^{\circ} \mathrm{C}$, slightly depressing seed germination in

Table 3. Regression analysis parameters of cumulative germination values $v s \theta_{\mathrm{T}}$.

\begin{tabular}{|c|c|c|c|c|c|c|}
\hline \multirow[b]{2}{*}{ Cultivar } & \multicolumn{3}{|c|}{ UP } & \multicolumn{3}{|c|}{ P } \\
\hline & a & $\mathrm{x}_{0}$ & $R^{2}$ & $\mathbf{a}$ & $\mathbf{x}_{0}$ & $\mathbf{R}^{2}$ \\
\hline Padana 4 & 109.1 & 20.4 & 0.79 & 91.6 & 12.6 & 0.75 \\
\hline PR $811 F$ & 94.9 & 26.2 & 0.98 & 92.6 & 12.4 & 0.96 \\
\hline Jumbo & 102.1 & 16.8 & 0.77 & 96.5 & 9.2 & 0.85 \\
\hline PSE 24213 & 89.1 & 35.5 & 0.71 & 87.8 & 16.8 & 0.88 \\
\hline
\end{tabular}

UP, unprimed seeds; P, osmoprimed seeds.
UP (76.3\%, on average of cultivars). Indeed, although seeds reached thermal time requirements for germination in a shorter period (MET 10.4 days) as compared to those of the $1^{\text {st }}$ planting, they were partially penalized by an even brief period (3 days) of quite low minimum temperatures $\left(7.3-7.8^{\circ} \mathrm{C}\right)$, that adversely affected seed germination in most of cultivars. With the latest sowings (mid-April and early May), minimum soil temperatures during the first ten days after planting were warmer, always over exceeding minimum threshold for seed germination of sorghum and thus allowing a regular seed germination in UP seeds as well. In particular, with the planting of early May, seedlings emerged from soil after 6.9 days, and a final $82.7 \%$ emergence (average of cultivars) was achieved in UP, under soil temperatures close to the optimal for seed germination, the $15 \%$ lower than laboratory germination at $25^{\circ} \mathrm{C}$. Similar differences between laboratory germination and the percentage field emergence (this last about 7\% lower) were described by Kanemasu et al. (1975) on early to late cultivars of sorghum.

Seed osmopriming before sowing enhanced seed germination under uncontrolled temperatures as well, although in a less extent as compared to the results obtained under controlled temperatures in laboratory. Its beneficial effect on seedling emergence was significant under the relatively cold soil of March ( $1^{\text {st }}$ and $2^{\text {nd }}$ sowings). In particular in the $2^{\text {nd }}$ planting, osmopriming compensated for the adverse effect of low minimum soil temperatures, inducing in seeds of $\mathrm{P}$ a $+13 \%$ seedling emergence increase as respect to those of UP. Seed osmopriming always enhanced the germination speed in all planting dates. Hardegree and Van Vactor (2000) reported a similar germination

Table 4. Effects of sowing date and seed treatment on seedling emergence percentage in four cultivars of fiber sorghum.

\begin{tabular}{|c|c|c|c|c|c|c|c|c|c|c|c|c|}
\hline \multirow[b]{3}{*}{ Cultivar } & \multicolumn{12}{|c|}{ Seedling emergence (\%) } \\
\hline & \multicolumn{3}{|c|}{$1^{\text {st }}$ sowing (March 10$)$} & \multicolumn{3}{|c|}{$2^{\text {nd }}$ sowing(March 28) } & \multicolumn{3}{|c|}{$3^{\text {rd }}$ sowing (April 15) } & \multicolumn{3}{|c|}{$4^{\text {th }}$ sowing (May 2) } \\
\hline & UP & P & Mean & UP & $\mathbf{P}$ & Mean & UP & $\mathbf{P}$ & Mean & UP & $\mathbf{P}$ & Mean \\
\hline Padana 4 & 72.7 & 81.3 & $77.0^{c}$ & 80.7 & 86.0 & $83.3^{\mathrm{b}}$ & 78.0 & 83.3 & $80.7^{\mathrm{b}}$ & 83.3 & 86.0 & $84.7^{\mathrm{b}}$ \\
\hline PR $811 F$ & 72.7 & 72.7 & $72.7^{\mathrm{c}}$ & 66.0 & 81.3 & $73.7^{\mathrm{b}}$ & 85.3 & 86.0 & $85.7^{\mathrm{b}}$ & 78.7 & 76.0 & $77.3^{\mathrm{b}}$ \\
\hline Jumbo & 88.7 & 92.0 & $90.3^{\mathrm{a}}$ & 86.0 & 96.0 & $91.0^{\mathrm{a}}$ & 94.0 & 96.7 & $95.3^{\mathrm{a}}$ & 88.0 & 95.3 & $91.7^{\mathrm{a}}$ \\
\hline PSE 24213 & 82.7 & 88.0 & $85.3^{\mathrm{b}}$ & 72.7 & 80.7 & $76.7^{\mathrm{b}}$ & 78.0 & 82.7 & $80.3^{b}$ & 80.7 & 79.3 & $80.0^{\mathrm{b}}$ \\
\hline Mean & $79.2^{\mathrm{b}}$ & $83.5^{\mathrm{a}}$ & & $76.3^{b}$ & $86.0^{\mathrm{a}}$ & & 83.8 & 87.2 & & 82.7 & 84.2 & \\
\hline \multicolumn{13}{|l|}{ Significance } \\
\hline Cultivar (cv) & $* * *$ & & & $* * *$ & & & $* *$ & & & $* *$ & & \\
\hline Seed treatment $(\mathrm{t})$ & * & & & $* *$ & & & ns & & & ns & & \\
\hline cv x t & ns & & & ns & & & ns & & & ns & & \\
\hline
\end{tabular}

UP, unprimed seeds; P, osmoprimed seeds; a,b, cifferent letters indicate significant differences at 0.05 level according to the Student-Newman-Keuls (SNK) test; * P $\leq 0.05 ; * * \mathrm{P} \leq 0.01$; *** $\leq 0.001$; ns, not significant.

Table 5. Effects of sowing date and seed treatment on mean emergence time in four cultivars of fiber sorghum.

\begin{tabular}{|c|c|c|c|c|c|c|c|c|c|c|c|c|}
\hline \multirow[b]{3}{*}{ Cultivar } & \multicolumn{12}{|c|}{ MET (days) } \\
\hline & \multicolumn{3}{|c|}{$1^{\text {st }}$ sowing (March 10) } & \multicolumn{3}{|c|}{$2^{\text {nd }}$ sowing(March 28) } & \multicolumn{3}{|c|}{$3^{\text {rd }}$ sowing (April 15) } & \multicolumn{3}{|c|}{$4^{\text {th }}$ sowing (May 2) } \\
\hline & UP & $\mathbf{P}$ & Mean & UP & $\mathbf{P}$ & Mean & UP & $\mathbf{P}$ & Mean & UP & $\mathbf{P}$ & Mean \\
\hline Padana 4 & 18.5 & 14.4 & $16.5^{\mathrm{a}}$ & 10.9 & 7.1 & 9.0 & 9.9 & 5.7 & 7.8 & 7.0 & 5.7 & $6.4^{\mathrm{a}}$ \\
\hline PR $811 F$ & 17.2 & 13.4 & $15.3^{\mathrm{ab}}$ & 10.1 & 7.6 & 8.8 & 9.3 & 6.9 & 8.1 & 7.3 & 5.3 & $6.3^{\mathrm{a}}$ \\
\hline Jumbo & 16.4 & 13.3 & $14.8^{\mathrm{b}}$ & 10.3 & 7.2 & 8.7 & 9.9 & 6.3 & 8.1 & 6.2 & 5.6 & $5.9^{b}$ \\
\hline PSE 24213 & 15.7 & 13.2 & $14.5^{b}$ & 10.5 & 7.1 & 8.8 & 9.6 & 5.6 & 7.6 & 7.2 & 5.1 & $6.2^{2 \mathrm{~b}}$ \\
\hline Mean & $17.0^{\mathrm{a}}$ & $13.6^{\mathrm{b}}$ & & $10.4^{\mathrm{a}}$ & $7.2^{b}$ & & $9.7^{\mathrm{a}}$ & $6.1^{\mathrm{b}}$ & & $6.9^{\mathrm{a}}$ & $5.5^{b}$ & \\
\hline \multicolumn{13}{|l|}{ Significance } \\
\hline Cultivar (cv) & * & & & ns & & & ns & & & * & & \\
\hline Seed treatment $(\mathrm{t})$ & $* * *$ & & & $* * *$ & & & $* * *$ & & & $* * *$ & & \\
\hline $\operatorname{cvxt}$ & ns & & & ns & & & ns & & & *** & & \\
\hline
\end{tabular}

MET, mean emergence time; UP, unprimed seeds; P, osmoprimed seeds; a,b different letters indicate significant differences at 0.05 level according to the Student-Newman-Keuls (SNK) test; * $\leq \leq 0.05 ; * * * 30.001 ;$ ns, not significant. 
enhancement following seed priming, but significant in earlier, cooler planting dates only, in grass seeds. Thomas and Christiansen (1971) as well, found that under field conditions, preconditioned seeds of cotton emerged at a faster rate than seeds that were not preconditioned, and that preconditioning enhanced overall crop performance throughout the growing season, thus suggesting that by increasing seed moisture, satisfactory stands of the crop may be achieved under suboptimal thermal conditions. Similar beneficial effects of seed osmoconditioning on seedling emergence and crop growth were also observed in castorbean under early sowings in open field (Patanè et al., 1996). Seed osmopriming also reduced thermal time requirements until the first seedling emerged from soil, in all cultivars (Table 6). Moreover, it slightly reduced the variability among planting dates (CV approximately $3 \%$ lower in $\mathrm{P}$ than in UP) for $\theta_{\mathrm{T}}$, due to sowing date.

Differently than laboratory results, the differences in seedling emergence due to cultivars always exceeded the 0.95 level of significance. The differences may be ascribed to a lower seed vigor observed in some cultivars in uncontrolled conditions (e.g. $P R$ 811F), especially under the earliest sowings, which resulted in a poorer seed germination and seedling emergence than in Petri dishes. Similar differences between laboratory and field experiment results were reported in cultivars of grain sorghum by Dunbabin et al. (1994). Among cultivars studied, Jumbo, with a lower $\theta_{\mathrm{T}}$, exhibited an overall higher seedling emergence ( $>85 \%$ in UP and $>90 \%$ in P) in all planting dates.

Low temperatures corresponded to early sowings resulted in a slower seedling growth and thus a smaller seedling mass (Table 7). Seed osmopriming promoted significantly the seedling weight in all cultivars and sowing dates $(c v \times t$ interaction not significant). Cultivars differed for this trait in the $2^{\text {nd }}$ and $4^{\text {th }}$ sowings. Jumbo, although producing a higher number of seedlings emerged, exhibited significantly smaller seedlings in both sowings. Emergence and seedling growth in sorghum

Table 6. Effects of seed treatment on thermal time $\left(\theta_{\mathrm{T}}\right)$ requirements (average of sowings dates) until the first emergence event in soil in four cultivars of fiber sorghum.

\begin{tabular}{|c|c|c|}
\hline Cultivar & & \\
\hline & UP & $\mathbf{P}$ \\
\hline Padana 4 & $74.2 \pm 9.7$ & $52.1 \pm 5.4$ \\
\hline PR $811 F$ & $77.2 \pm 11.1$ & $54.2 \pm 6.3$ \\
\hline Jumbo & $67.3 \pm 6.8$ & $47.4 \pm 3.3$ \\
\hline PSE 24213 & $77.9 \pm 11.4$ & $54.7 \pm 6.5$ \\
\hline
\end{tabular}

UP, unprimed seeds; P, osmoprimed seeds. under low-temperature stress were suggested to be under different genetic control (Yu et al., 2004), indicating that it is possible to combine different components in breeding programs for cold tolerance in sorghum.

\section{Conclusions}

The results obtained from the research suggest that the minimum temperature required for seed germination of the four cultivars of sorghum in laboratory is around in $8-10^{\circ} \mathrm{C}$. However, the slow rate of seed germination in field indicates that higher temperatures are required for seedling emergence from soil. Seeds took advantage of osmopriming in terms of germination and emergence speed, more than in terms of final emergence percentage, which is anyway a relevant aspect to take into account when early sowing are adopted in sorghum. Osmopriming also allowed seeds to recover from short chilling periods during germination in soil. This is an important aspect in the cultivation of sorghum, since soil temperature fluctuations occurring in a particular cultivation area may strongly affect stand establishment in sorghum, especially when early plantings are adopted.

Therefore, the possibility to promote germination and fasten the rate of seedling emergence in field by osmopriming the seeds should be considered, since this treatment may also allow the seeds to avoid damages due to soil-born organisms during an extended seed germination under low soil temperatures. Although the germination response to constant low temperatures in laboratory tests does not always provide a good index for predicting seedling emergence in soil under fluctuating uncontrolled temperatures, it may contribute to define desirable attributes for the identification of cultivars adapt to early sowings in the Mediterranean areas. To this respect, the results of this research indicate the aptitude of the four cultivars of sorghum to well adapt to cold soil.

The identification of cultivars with satisfactory levels of cold tolerance and thus suitable for early-spring sowings and the feasibility to improve seedling emergence under cool soil by osmopriming the seeds may contribute to the extension of this crop into the production areas of the semi-arid Mediterranean regions. The identification of desirable traits for cold tolerance in field during the early stages of growing season (i.e. high seedling emergence percentage or rate, high seedling growth rate) to transfer to high-yielding cultivars of sorghum, may be also considered in breeding programs for the selection of new cultivars also adapt to frost-free temperate zones of central Europe, where low soil temperatures restrict germination and stand establishment.

Table 7. Effects of sowing date and seed treatment on seedling dry weight, in four cultivars of fiber sorghum.

\begin{tabular}{|c|c|c|c|c|c|c|c|c|c|c|c|c|}
\hline \multirow[b]{2}{*}{ Cultivar } & \multicolumn{3}{|c|}{$1^{\text {st }}$ sowing (March 10) } & \multicolumn{5}{|c|}{ Seedling dry weight (mg) } & (il 15) & \multicolumn{3}{|c|}{$4^{\text {th }}$ sowing (May 2 ) } \\
\hline & UP & $\mathrm{P}$ & Mean & UP & $\mathrm{P}$ & Mean & UP & $\vec{P}$ & Mean & UP & $\mathbf{P}$ & Mean \\
\hline Padana 4 & 9.5 & 10.3 & 9.9 & 25.9 & 31.1 & $28.5^{\mathrm{a}}$ & 29.8 & 33.3 & 31.5 & 52.5 & 56.5 & $54.5^{\mathrm{b}}$ \\
\hline PR $811 F$ & 9.7 & 12.6 & 11.1 & 25.0 & 28.3 & $26.6^{\mathrm{a}}$ & 32.7 & 35.2 & 34.0 & 55.9 & 58.6 & $57.3^{\mathrm{ab}}$ \\
\hline Jumbo & 8.6 & 10.3 & 9.5 & 21.0 & 23.4 & $22.2^{b}$ & 30.3 & 33.4 & 31.9 & 47.7 & 49.4 & $48.6^{c}$ \\
\hline PSE 24213 & 8.8 & 11.3 & 10.1 & 26.9 & 30.6 & $28.8^{\mathrm{a}}$ & 31.2 & 39.4 & 35.3 & 56.6 & 66.5 & $61.6^{\mathrm{a}}$ \\
\hline Mean & $9.2^{\mathrm{b}}$ & $11.1^{\mathrm{a}}$ & & $24.7^{\mathrm{b}}$ & $28.4^{\mathrm{a}}$ & & $31.0^{\mathrm{b}}$ & $35.3^{\mathrm{a}}$ & & $53.2^{\mathrm{b}}$ & $57.8^{\mathrm{a}}$ & \\
\hline \multicolumn{13}{|l|}{ Significance } \\
\hline Cultivar (cv) & ns & & & $* * *$ & & & ns & & & $* * *$ & & \\
\hline Seed treatment (t) & $* * *$ & & & $* * *$ & & & $* *$ & & & $* *$ & & \\
\hline cvxt & ns & & & ns & & & ns & & & ns & & \\
\hline
\end{tabular}

UP, unprimed seeds; , osmoprimed seeds; a,b,c, different letters indicate significant differences at 0.05 level according to the Student-Newman-Keuls (SNK) test; **P $\leq 0.01 ; * * *$ P $\leq 0.001$; ns, not significant. 
Khan AA, Satriyas I, Ptasznik W, 1995. Integrating low water potential seed hydration with other treatments to improve cold tolerance. Ann. Bot. 75:13-19.

Bacon RK, Cantrell RP, Axtell JD, 1986. Selection for seedling tolerance in grain sorghum. Crop Sci. 26: 900-903.

Bradford KJ, 1986. Manipulation of seed water relations via osmotic priming to improve germination under stress conditions. Hort. Sci. 21:1105-1112.

Brar GS, Stewart BA, 1994. Germination under controlled temperature and field emergence of 13 Sorghum cultivars. Crop Sci. 34:13361340.

Bujalski W, Nienow AW, 1991. Large-scale osmotic priming of onion seeds: a comparison of different strategies for oxygenation. Sci. Hortic. 46:13-24.

Cosentino SL, 1996. Crop physiology of sweet sorghum [Sorghum bicolor (L.) Moench]. pp 30-41 in Proc. 1st Eur. Seminar on Sorghum for Energy and Industry, Toulose, France.

Cosentino SL, Copani V, Mantineo M, Foti S, 2002. Risposta di una coltura di sorgo [Sorghum bicolor (L.) Moench] a diversi livelli di energia ausiliaria. Riv. Agron. 36:357-365.

Cosentino SL, Copani V, Patanè C, Mantineo M, D'Agosta G, 2008. Agronomic, energetic and environmental aspects of biomass energy crops suitable for Italian environments. Ital. J. Agron. 3:81-95.

Cosentino SL, Patanè C, Guarnaccia $P, 1996$. Biomass, leaf area index and water use efficiency of sweet sorghum in limited water availability in Mediterranean environment. pp 228-235 in Proc. 1st Eur. Seminar on Sorghum for Energy and Industry, Toulose, France.

Dunbabin T, Learmonth J, Naylor REL, Mullins CE, 1994. Temperature effects on the germination of Sorghum bicolor under constant temperatures regimes. Aspect Appl. Biol. 39:179-186.

Ercoli L, Mariotti M, Masoni A, Arduini I, 2004. Growth responses of sorghum plants to chilling temperature and duration of exposure. Eur. J. Agron. 21:93-103.

Foti S, Cosentino SL, Patanè C, D'Agosta G, 2002. Effect of osmoconditioning upon seed germination of sorghum [Sorghum bicolor (L.) Moench] under low temperatures. Seed Sci. Technol. 30:521-533.

Hardegree SP, Van Vactor SS, 2000. Germination and emergence of primed grass seeds under field and simulated-field temperature regimes. Ann. Bot. 5:379-390.

ISTA, 1996. International rules for seed testing. Seed Sci. Technol. 24(Suppl.):1-86.

Kanemasu ET, Bark DL, Chin Choy E, 1975. Effect of soil temperature on sorghum emergence. Plant Soil 43:411-417.

Mantineo M, D’Agosta GM, Copani V, Patanè C, Cosentino SL, 2009. Biomass yield and energy balance of three perennial crops for energy use in the semi-arid Mediterranean environment. Field Crop Res. 114:204-213.

Michel BE, Kaufmann MR, 1973. The osmotic potential of polyethylene glycol 6000. Plant Physiol. 51:914-916.

Patanè C, Cavallaro V, Avola G, D'Agosta G, 2006. Seed respiration of sorghum [Sorghum bicolor (L.) Moench] during germination as affected by temperature and osmoconditioning. Seed Sci. Res. $16: 251-260$.

Patanè C, Cavallaro V, Cosentino SL, 2009. Germination and radicle growth in unprimed and primed seeds of sweet sorghum as affected by reduced water potential in $\mathrm{NaCl}$ at different temperatures. Ind. Crop Prod. 30:1-8.

Patanè C, Cavallaro V, D’Agosta G, Cosentino SL, 2008. Plant emergence of PEG-osmoprimed seeds under suboptimal temperatures in two cultivars of sweet sorghum differing in seed tannin content. J. Agron. Crop Sci. 194:304-309.

Patanè C, Sortino 0, Abbate V, 1996. Valutazione delle caratteristiche germinative del seme di ricino osmocondizionato ai fini dell'adattamento alla semina autunno-vernina. Riv. Agron. 3:264-269.

Saita A, Patanè C, Guarnaccia P, 2011. Genotypes screening for cold tolerance during germination in sorghum [Sorghum bicolor (L.) Moench] for energy biomass. pp 552-555 in Proc. 19th Eur. Biomass Conf. and Exhibition, Berlin, Germany.

Scott SJ, Jones RA, Williams WA. 1984. Review of data analysis methods for seed germination. Crop Sci. 24:1192-1198.

Singh NT, Aggarwal GC, Brar GS, 1984. Effect of soil moisture stress on heat unit requirement of wheat at maturity. Indian J. Agric. Sci. 54:442-444.

Singh SP, 1985. Sources of cold tolerance in grain sorghum. Can. J. Plant Sci. 65:251-257.

Snedecor GW, Cochran WG, 1989. Statistical methods, 8th ed. Iowa State University Press, Ames, IA, USA.

Thomas RO, Christiansen MN, 1971. Seed hydration-chilling treatment effects on germination and subsequent growth of cotton. Crop Sci. 11:454-456.

Yu J, Tuinstra MR, Claassen MM, Gordon WB, Witt MD, 2004. Analysis of cold tolerance in sorghum under controlled environment conditions. Field Crop Res. 85:21-30. 